\title{
LEXEME MEIN- PART-OF-SPEECH APPURTENANCE IN THE MODERN GERMAN GRAMMAR IN THE FRAMEWORK OF OPTIMALITY THEORY
}

\author{
Oksana Turysheva \\ National Technical University of Ukraine "Igor Sikorsky Kyiv Polytechnic Institute”, Kyiv, Ukraine \\ turysheva.kpi@gmail.com
}

\begin{abstract}
This paper focuses on the determination of the part-of-speech appurtenance of MEIN-lexeme concerning the Optimality Theory. The aim of the analysis is also to find the solution to the problem in the frame of a new course of formal research which appeared in the beginning of 90 -s years of the 20-th century (the Optimality Theory) by using its methodological terms. The following working hypothesis was made: MEIN belongs to an article class. The constraints were formulated on the basis of main article characteristics presented in various German grammars. According to multifunctional nature of a lexeme, the constraints combine morphological, syntactic and semantic features: an article can't be the head of a noun phrase, it agrees with a noun in case, gender and number, has no lexical meaning, affects the inflection of the adjective in the attributive position, doesn't coordinate with other articles, has the function of determination, can be moved into an A-position only as a part of noun phrase. The results are made in the form of tables that present the process of harmony-evaluation and the final optimal candidate. The results of the study show that MEIN- lexeme belongs to an article class. It is equally important that the methodological tools of the Optimality Theory could be extended for research in the sphere of morphology and semantics.
\end{abstract}

Keywords: the optimality theory; the part of speech; pronoun; article; constrains; evaluation.

\section{Introduction}

Lexeme MEIN- part-of-speech appurtenance regarding German grammar did not generate a lot of debates 15-20 years ago (the lexeme considered to be a pronoun, possessive pronouns subclass). Nowadays, due to the variety of advanced approaches to study and interpretation of language patterns, this issue has been investigated from a new perspective. A perennial problem of parts-of-speech classification has been relevant more than two thousand years and in combination with new approaches to a scientific inquiry, this issue gives us a new horizon for linguistic study. Therefore, the underlying assumption of our research is indeterminacy of part-of-speech appurtenance of lexeme MEIN- and its terminological ambiguity.

We are trying to find the solution to the problem in the frame of a new course of formal research which is not popular in Ukraine whereas foreign researchers are actively developing this study. We will conduct our research through Optimality Theory - the grammar theory which appeared in the beginning of 90-s years of the 20-th century.

The aim of the paper is to determine of part-of-speech appurtenance of MEIN-lexeme concerning Optimality Theory. We advance the following working hypothesis: MEIN belongs to an article class. Besides, we suppose that methodological tools of this theory can be expanded by an introduction of new constraints (an important component of choice process of an optimal candidate within Optimality Theory).

The presented issue has not been thoroughly investigated in terms of Optimality Theory in linguistics. Thus, Gereon Müller studied pronominal adverbs "Das Pronominaladverb als Reparaturphänomen" (2000), Heide Wegener examined the issue of nouns plural forms in German language "Die Pluralbildung im Deutschen - ein Versuch im Rahmen der Optimalitätstheorie" (1999), general aspects of Optimality Theory were described by Kevin Russell "Optimality Theory and Morphology" (1997), Dieter Wunderlich "Optimality theory in morphology and syntax" (2004), Zheng Xu "Optimality Theory and Morphology" (2011). As we see, the fundamental issue of a scientific exploring has not been under investigation regarding linguistics.

\section{Methods}

We present the paper to determine the part of speech for the lexeme MEIN- by the application of Optimality Theory methodological terms. Optimality Theory is a grammar theory originated from works "Optimality Theory: Constraint Interaction in Generative Grammar" by Alan Prince and Paul Smolensky and "Prosodic Morphology I: Constraint Interaction and Satisfaction" by John McCarthy and Alan Prince in 1993.

Optimality Theory (OT) arose on the basis of Generative Grammar. The key statement of OT is: "The basic idea we will explore is that Universal Grammar (UG) consists largely of a set of constraints on representational well-formedness, out of which individual grammars are constructed" (Prince, 2004, p. 2). 
This theory is particularly popular among researchers from different linguistic schools. Phonology is considered to be the first objective of OT researches (Prince \& Smolensky, 1993, 2004; MacCarty \& Prince, 1994, 1995; MacCarty, 1991, 2001, 2007; Kager, 1999; Prince, 2002, 2007 et al.). Later it was syntax (Grimshaw, 1997, 1999; Müller, 1997, 1999, 2000, 2001, 2002, 2003; Legendre, Grimshaw \& Vikner, 2001; Blutner et al., 2006; Legendre, 1998, 2001 et al.).

An axiom represents an initial issue for the cognition of the theory that any language is an organism which functions according to certain algorithms constructed from all rules and consistent patterns with their conditions, constraints, and exceptions. Another important thesis claims that all utterances have different forms of expression. Therefore, it is variative by nature. Any language grammar is a hierarchic system of constraints which can be violated. The constraints are of universal nature but within a certain language the constraints system has its own hierarchy (Prince, 1997, p. 1604). The main purpose of these constraints is to determine what features should not be in an utterance. Grammar "correctness/incorrectness" of a candidate is solely reflected by resolutions of conflicts between competing constraints - from left to right, from the most important to less important. In theory, the number of candidates is unlimited. That candidate which violates less "severe" constraints wins the competition and is considered to be optimal (i.e., there is only one optimal variant for an utterance).

Briefly, the fundamental properties of OT are as following:

INPUT - GENERATOR - OUTPUT $\left(\mathrm{O}_{1}, \mathrm{O}_{2}, \mathrm{O}_{3}, \ldots \mathrm{O}_{\mathrm{n}}\right)$ - HARMONY-EVALUATION - OUTPUT I $_{\mathrm{I}}$ the optimal output)

OT model is presented with two operational components: generator (GEN) and harmony-evaluation (HEVAL). GEN introduces the input data as a set of unlimited number of candidates. H-EVAL selects an optimal candidate as the output of the grammar. Each component has its characteristics which should be strictly followed to obtain reliable results, while the evaluation of each candidate receives its constraint ranking. The candidate with the "best" constraint ranking is considered as an optimal.

Prior to our research object analysis within OT, it is essential to review its aspects in terms of standard grammar and other grammar theories. In order to avoid interpretation differences, we have to mention that additive combinations and MEINER-lexemes (e.g., Gib mir den Kugelschreiber! - Nein! Das ist meiner!) are not the case of this paper.

\section{Results}

With reference to functional grammar ("Grammatik der deutschen Sprache", 1997, G. Zifonun, L. Hoffmann, B. Strecker et.al.), the parts of speech differentiation comes about a principle of semantic and pragmatic approaches of a language utterance. The prototype functions are the classification criteria (Zifonun, 1997, p. 21-22). According to criteria <+/- part of minimal communicative unit > all words are unitized into the parts of speech and interactive units. With a view of presenting more detailed parts-ofspeech characteristics authors enrol morphological (<+/- inflection>, <+/- conjugation>, <+/- comparison> etc.) and syntactic criteria (<+/- case governing $>,<+/$ - ability to be an utterance nuclear $>$, etc.).

The authors of the mentioned Grammar book regard MEIN- lexeme as a determiner class with a subcategory as a possessive determiner. MEIN- is recognised as possessive determiner: " [...] trägt zur Gegenstandsbestimmung dadurch bei, dass eine spezifische Zugehörigkeitsrelation zum Sprecher (mein), zum Adressaten (dein/Ihr) oder entsprechenden Gruppen (unser, euer/Ihr) hergestellt wird, [...]" (Zifonun, 1997, p. 35).

Correspondingly, MEIN- presents the following features:

$-<+$ a part of a minimal communicative unit $>$

$-<+$ inflection>

$-<$ - conjugation $>$

$-<$ - comparison>

$-<-$ case governing>

$-<-$ a head of a noun phrase >

The work "Deutsche Grammatik" (2011), written by Gerhard Helbig and Joachim Buscha, introduces the part-of-speech classification based on syntactic criteria taking into consideration the location and distribution of speech chain elements in linear deployment.

According to the classification MEIN- is regarded as a class of functional words, articles subtype, adjective possessive pronoun. In this grammar adjective possessive pronouns have the following features:

1) located directly in front of the noun they refer to (even if not immediate in front);

2) not preceded with an article;

3) change their location in the sentence only in combination with a noun; 
4) match all noun forms: case, gender and number;

5) their presence is obligatory (as a zero article);

6) restricted by marking the attributing possession to someone or something (Helbig, 2011, p. 320-322).

With regards to statements of dependent grammar, Ulrich Engel offers an advantage to syntactic criteria for part-of-speech classification ("Syntax der deutschen Gegenwartssprache", 2009). In his opinion, the most appropriate method of classification is based on systematically regulated (potential, not actual) words enclosing, in other words, distribution. "Wenn man allerdings die Umgebung der Wörter systematisch und umfassend versteht, lässt sich daraus eine brauchbare Wortklassifikation gewinnen, die zu eindeutigen Teilmengen führt" (Engel, 2009, p. 39). A lexeme is a unit of his classification.

Engel considers MEIN- as a determiner. His system of parts of speech ranking is based on the scheme: "question- strainer" which reveals the most significant parts of speech characteristics. An affirmative answer to a question correlates the lexeme to an exact part of speech automatically. Thus, determiner is separated by an affirmative answer to a question (strain \#3) "A word is inconsistent with "Saxon genitive"?" which Engel determined as genitive ending in pre-position:

Concerning the mentioned above, MEIN- acquires the following features:

1) it cannot be conjugative (due to a negative answer to the first strain);

2) it does not demonstrate the constant gender (as a result of a negative answer to the second strainer);

3 ) it is incompatible with Saxon genitive (because of a positive answer to the third strain).

The issue of selection and part-of-speech classification was the objective of studies of the generativists (Stechow 1988, Jackendoff 1977, Radford 1998, Stenzel 1995, Zimmermann 2004). The main criteria for the parts of speech selection are:

$+/-\mathrm{V}($ verbal $)$

$+/-\mathrm{N}$ (nominal)

The detailed information is presented in the article "Parts of speech in generative grammar" (Turysheva, 2016, p. 349-360) that determines the status of the parts of speech in the generative grammar and clarifies the content and the significance of the features $[+/-\mathrm{N} / \mathrm{V}]$.

In general, within the Generative Grammar, there are four parts of speech or lexical categories:

\begin{tabular}{|l|l|l|}
\hline & \multicolumn{1}{|c|}{$-\mathrm{V}$} & \multicolumn{1}{c|}{$+\mathrm{V}$} \\
\hline$-\mathrm{N}$ & $\mathrm{P}=[-\mathrm{N},-\mathrm{V}]$ & $\mathrm{V}=[-\mathrm{N},+\mathrm{V}]$ \\
\hline$+\mathrm{N}$ & $\mathrm{N}=[+\mathrm{N},-\mathrm{V}]$ & $\mathrm{A}=[+\mathrm{N},+\mathrm{V}]$ \\
\hline
\end{tabular}

Table 1

Andrew Redford ("Syntactic theory and the structure of English. A minimalist approach", 2002) added one more feature $[+/-F]$ to part-of-speech classification with a view to differentiating functional and semantic words with conceptual meaning. Redford claims that all functional words are "[...] words which serve primarily to carry information about the grammatical properties of expressions within the sentence, for instance, information about the number, gender, person, case, etc." (Radford, 2002, p. 45). Thus, general part-of-speech classification contains four lexical and four functional categories with the following features (Radford, 2002, p. 64):

Table 2

\begin{tabular}{|l|l|l|l|}
\hline \multicolumn{2}{|c|}{ Lexical categories } & \multicolumn{2}{c|}{ Functional categories } \\
\hline Noun/N & {$[+\mathrm{N},-\mathrm{V},-\mathrm{F}]$} & Pronoun/PRN & {$[+\mathrm{N},-\mathrm{V},+\mathrm{F}]$} \\
\hline Adjective/A & {$[+\mathrm{N},+\mathrm{V},-\mathrm{F}]$} & Determiner/DET & {$[+\mathrm{N},+\mathrm{V},+\mathrm{F}]$} \\
\hline Verb/V & {$[+\mathrm{V},-\mathrm{N},-\mathrm{F}]$} & Auxiliary/AUX & {$[-\mathrm{N},+\mathrm{V},+\mathrm{F}]$} \\
\hline Preposition/P & {$[-\mathrm{N},-\mathrm{V},-\mathrm{F}]$} & Particle/C/I & {$[-\mathrm{N},-\mathrm{V},+\mathrm{F}]$} \\
\hline
\end{tabular}

In conformity with the presented characteristics MEIN-lexeme belongs to a class of functional categories, pronoun subtype with such features:

1) it is a case determinant;

2) it makes possible so-called "cleft-sentence";

3 ) it stores the information about grammar utterance characteristics within a sentence.

Dudengrammatik (Kunkel-Razum \& Münzberg, 2009) differentiates lexical and syntactic parts of speech. MEIN- belongs to a lexical part of speech "article and pronoun". The necessity of double name by the attempt to avoid complications of multi-meaning of the term "pronoun" is supported (p. 249).

According to Dudengrammatik, the terms "article and pronoun" are used to point the lexical parts of speech and to perform more detailed differentiation with a projection to syntactic peculiarities of either 
"pronoun" or "article" and, along with this, there are "possessive articles" and "possessive pronouns". Based upon the morphological criteria, grammar authors apply both criteria syntactic and semantic as well to select subtypes within this part of speech.

"Possessives" are distinguished as (Kunkel-Razum \& Münzberg, 2009, p. 253):

- possessive article: Das ist mein Heft!

- possessive pronoun (restricted conception): Das ist meins!

- possessive nominative adjective (followed the article): Sie hat das Ihre geleistet!

The features of possessive article are (Kunkel-Razum \& Münzberg, 2009, p. 276-277):

- it formally matches the case, gender, and number of a noun;

- it takes the same position as an article (before the attributive adjective);

- it can semantically replace the definite article (person or object identification attributed by a noun).

Without a description of a possessive pronoun the authors state that such pronouns do not exist in German language in a "pure" form (Kunkel-Razum \& Münzberg, 2009, p. 279) and forms like Das ist meins! attribute to possessive article originated due to the noun phrase ellipsis.

Peter Gallmann is the author of some chapters of Dudengrammatik, including the chapter "Die flektierbaren Wortarten". To underline the importance and ambiguousness of this problem we present the other opinion of Gallmann. In Schülerduden Grammatik (Gallmann, P., Geipel M., Wagner A., 2010), he considers MEIN- as a possessive pronoun. One author, a one-year discrepancy and two different views! But changes in normative grammar don't occur so fast. This example confirms how complicated is the procedure of part-of-speech classification. It is a long and difficult process of search for a new paradigm.

Famous grammar researchers Hentschel and Weydt (2013) suggest cognitive principles as a basis for the classification. These principles are established in accordance with main semantic types:

- autosemantic: open classes;

- deictic: closed classes;

- categorical: open classes;

- synsemantic: closed classes (p.14-15).

In general, they accept tradition article and pronoun differentiation. MEIN-lexeme belongs to pronouns, possessive pronouns subclass. They possess deictic and categorical meaning apart from autosemantic as they both point out something without naming it (Hentschel, 2013, p. 19). It should be noted that regardless, such unusual approach to parts of speech selection, their characteristic is standard and does not significantly differ from so-called "traditional" approach to the issue.

Sommerfeld, Starke and Hackel (1998) issue from the fact that the most words have a lexical meaning which is a base for part of speech meaning. They correspond parts of speech with categorical meaning according to the principle: a noun - subject, a verb - process, an adjective - feature (p. 40).

The authors specify that these categorical meanings distort the objective reality data. These abstractive categorical senses receive some additional categorical features, which are reflected by grammatical categories of corresponded parts of speech. They also emphasise that the categorical meaning determination is not enough for proper classification. So, in order to give a full characteristic to each part of speech, Sommerfeld, Starke and Hackel (1998) suggest taking into consideration formal and grammar features (p. 41). The authors rate MEIN-lexeme as a pronoun, possessive pronoun subclass (p. 19).

We will now proceed to constraints formulation which is necessary for candidate evaluation. It should be noted that the main feature of any constraint is its universality. Consequently, constraints are formed on the basis of main article characteristics taking into account the pointed feature. Thus, according to universal characteristic an article:

1) cannot be a head of a noun phrase (NP);

2) agrees with a NP head in case, gender and number;

3) has no lexical meaning;

4) determines the attributive adjective declension (specifically for German language);

5) cannot be combined with other articles;

6) has a semantic function of referent determination;

7) can be syntactically displaced only as a part of NP.

On the basis of information mentioned above, we can formulate such constraints:

- NP-Head-Forbid (can't be the head of NP);

- N-Agree (noun agreement in case, gender and number);

- LM-Abs (the absence of a lexical meaning);

- Adj-Infl (affects the inflection of the adjective in the attributive position);

- Art-Coord-Forbid (the coordination with other articles is forbidden); 
- RD-Function (the function of determination);

- NP-Mov (a movement of an article into an A-position is possible only as a part of NP).

Keeping in mind the concept that any lexeme is multifunctional by nature and formal and grammatically diverse, constraints correspond the lexeme and combine morphological, syntactic and semantic features. Such diversity of our scientific inquiry complicates the constraints hierarchy process. In order to solve the problem, we suggest differentiating morphological, syntactic and semantic constraints. Therefore, instead of one multivalued hierarchy, we obtain three hierarchic systems relevant to German language:

1) morphological criterion: N-Agree $>$ Adj-Infl;

2) syntactic criterion: NP-Head-Forbid >> Art-Coord-Forbid >> NP-Mov;

3) semantic criterion: RD-Function > LM-Abs.

Consequently, the choice of an optimal candidate should correspond each criterion:

Table 3

\begin{tabular}{|c|c|c|c|}
\hline & $\begin{array}{l}\text { Constraints } \\
\text { Candidate set }\end{array}$ & N-Agree & Adj-Infl \\
\hline$\Rightarrow$ & Das ist mein neuer Wagen. & & \\
\hline & Der neue Wagen ist meiner. & & * \\
\hline & Das ist meiner neue* Wagen. & $* !$ & \\
\hline & Der neue Wagen ist mein. & $* !$ & * \\
\hline
\end{tabular}

Table 4

\begin{tabular}{|l|l|c|c|c|}
\hline & \multicolumn{1}{|c|}{ Constraints } & NP-Head-Forbid & NP-Mov & Art-Coord-Forbid \\
\hline$\Rightarrow$ & Candidate set & & & $*$ \\
\hline & Das ist mein neuer Wagen. & $* !$ & $*$ & $*$ \\
\hline & Der neue Wagen ist meiner. & & $* !$ & $*$ \\
\hline & Das ist meiner neue* Wagen. & $* !$ & $*$ & $*$ \\
\hline
\end{tabular}

Table 5

\begin{tabular}{|l|l|c|c|}
\hline & \multicolumn{1}{|c|}{ Constraints } & RD-Function & LM-Abs \\
\hline$\Rightarrow$ & Candidate set & & $*$ \\
\hline & Das ist mein neuer Wagen. & $* !$ & $*$ \\
\hline$\Rightarrow$ & Der neue Wagen ist meiner. & $* !$ & $*$ \\
\hline & Das ist meiner neue* Wagen. & $*$ ne Wagen ist mein. & \\
\hline
\end{tabular}

\section{Discussion}

Now we will progress to the interpretation of obtained results. According to a Table 3 the first candidate is optimal as it does not violate any constraint and wins the competition.

Table 4 presents the "victory" of the same candidate. However, an optimal candidate is also not "ideal" and violates constraint Art-Coord-Forbid. But taking into account the constraints hierarchy, it is the least "severe", so exactly the first candidate is considered to be optimal.

In a competition shown in the Table 5 we observe two winners. It is an unusual situation, but it confirms that research for polyfunctional units should be carried out considering all possible features which mark and specify them. It implies that if we carried out the analysis with a single projection on semantic characteristics, we would not achieve positive results.

Summing up the information mentioned above, the research found that two of seven analysed cases determine MEIN- as determiner class (Zifonun, Hoffmann, Strecker \& Ballweg, 1997; Engel, 2009), other two refer it to articles (Helbig, 2011; Kunkel-Razum \& Münzberg, 2009) and three cases evidence it as a pronoun (Hentschel, 2013; Sommerfeld, Starke \& Hackel, 1998; Radford, 2002). In our opinion, the notion "determiner" and "article" cannot be equalled because the first one is more extended than the second one and it can join more different lexemes. The differentiation of these two notions can be an issue of further studies. We have chosen the definition "article" because with a view of implementation the research results into the 
educational process it is the most appropriate solution due to its exact general and partial characteristics and further simplified subcategorization.

The perspective issue of the research is to carry out the optimal theoretic analysis of those lexemes which potentially can change (or have changed) their parts-of-speech appurtenance, e.g. numerals (der zweite, vier), the participle (der geschriebene Brief), all pronouns subclasses (according to traditional approach).

\section{Conclusion.}

Following presented results and their further interpretation, MEIN-lexeme belongs to an article class. In our opinion, results can be presented at grammar teaching lessons in secondary and high educational establishments. It is equally important that we possibly could extend the methodological tools of OT (evidenced in results) for research in the sphere of morphology and semantics which provide us with extending perspectives for further scientific inquiry.

\section{References:}

Engel, U. (2009). Syntax der deutschen Gegenwartssprache [The Syntax of modern German]. (4 $4^{\text {th }}$ ed.). Berlin, Germany: Erich Schmidt.

Helbig, G. \& Buscha, J. (2011). Deutsche Grammatik [German Grammar]. Berlin, Munich, Germany, Vienna, Austria, Zürich, Switzerland, New York, USA: Langenscheidt.

Hentschel, E. \& Weydt, H. (2013). Handbuch der deutschen Grammatik [Reference Grammar of German]. (4 ${ }^{\text {th }}$ ed.). Berlin, Germany, New York, USA: Walter de Gruyter. https://doi.org/10.1515/9783110312973

Kunkel-Razum, K. \& Münzberg, F. (Eds.) (2009). Die Grammatik. Unentbehrlich für richtiges Deutsch [Grammar. Indispensable for real German]. (8th ed.). Mannheim, Germany, Vienna, Austria, Zürich, Switzerland: Dudenverlag.

Prince A., \& Smolensky P. (2004). Optimality Theory. Constraint Interaction in Generative Grammar. Malden, MA, USA, Oxford, UK, Carlton, Vic., Australia: Blackwell Publishing. https://doi.org/10.1017/S0272263106220060

Prince A., \& Smolensky P. (1997). Optimality: From Neural Networks to Universal Grammar. Science, 275, $1604-1610$. https://doi.org/10.1126/science.275.5306.1604

Radford, A. (2002). Syntactic theory and the structure of English. A minimalist approach. Cambridge, UK: Cambridge University Press. https://doi.org/10.1017/CBO9781139166706

Sommerfeld, K.-E., Starke, G. \& Hackel W. (1998). Einführung in die Grammatik der deutschen Gegenwartssprache [Introduction to Grammar of the modern German]. ( $3^{\text {rd }}$ ed.). Berlin, Germany, New York, USA: Walter de Gruyter. https://doi.org/10.1515/9783110918861

Turysheva O. (2016). Parts of speech in generative grammar. Germanica Wratislaviensia. Ansätze - Begründungen - Maßstäbe, 141, 349-360. http://dx.doi.org/10.19195/0435-5865.141.23

Zifonun, G., Hoffmann, L., Strecker, B., \& Ballweg, J. (1997). Grammatik der deutschen Sprache [Grammar of German language]. (Vol. 3). Berlin, Germany, New York, USA: Walter de Gruyter. 